\title{
Penggunaan Metode Naïve Bayes untuk Memprediksi Tingkat Kemenangan pada Game Mobile Legends
}

\author{
Ahmad thoriq Susilo ${ }^{1}$, Hendra Setiawan ${ }^{2}$, Rizal Aji Saputro ${ }^{3}$, Tirto Purwadi $^{4}$, Aries Saifudin \\ Teknik Informatika, Universitas Pamulang, Tangerang Selatan, Indonesia \\ E-mail: ${ }^{1}$ thoriqsusilo0@gmail.com, ${ }^{2}$ hdrasetiawan@gmail.com, ${ }^{3}$ rizalaji313@gmail.com, \\ ${ }^{4}$ tirtopurwadi@gmail.com, ${ }^{5}$ aries.saifudin@unpam.ac.id \\ Submitted Date: November $19^{\text {th }}, 2020$ \\ Revised Date: November $25^{\text {th }}, 2020$ \\ Reviewed Date: November $24^{\text {th }}, 2020$ \\ Accepted Date: April 01 ${ }^{\text {st }}, 2021$
}

\begin{abstract}
The research conducted aims to predict the win or loss of a game in the Mobile Legend game. Because victory will greatly affect the level of play that is owned in the Mobile Legend game, and victory is also influenced by the player's ability to play the game and mastery of a game character that is used. The results of the study will show the results of the classification of the success rate of the method we use in predicting the success or victory of the game in the online game Mobile Legend which can be called the most popular game today. Many play this online game even from small children to adults. This game is very popular at this time, but there are still many who play while playing this game so that it greatly affects performance when doing battle games which results in many rankings dropping to the herro who doesn't move due to lag cellular network.
\end{abstract}

Keywords: Game; Naïve Bayes; Prediction; Winning

\section{Abstrak}

Penelitian yang kami lakukan bertujuan untuk memprediksi tingkat keberhasilan suatu permainan pada game Mobile Legend. Karena kemenangan akan sangat mempengaruhi level permainan yang dimiliki dalam game Mobile Legend, dan kemenanagan juga dipengaruhi oleh kemampuan pemain dalam bermain game dan penguasaan suatu carakter permainan yang di gunakan. Hasil dari penelitian akan menujukan hasil klasifikasi tingkat keberhasilan dari metode yang kami gunakan dalam memprediksi keberhasilan atau kemenangan permainan dalam game online Mobile Legend yang bisa di sebut game paling popular saata ini. Banyak sekali yang memainkan permainan game online ini bahkan dari anak kecil hingga dewasa game ini sangan popular pada saat ini, namun masih banyak kendala yang dihadapi saat bermain permainan game ini sehingga sangat mempengaruhi performa saat melakukan pertempuran didlam game yang mengakibatkan banyak rank yang turun hingga herro yang tak bergerak karena lag jaringan seluler.

Kata Kunci: Game; Kemenangan; Naïve Bayes; Prediksi

\section{Pendahuluan}

Untuk membantu pemain dapat mengetahui tingkat presentasi kemenangan tim pada permainan Mobile Legends. Sebagai salah satu game mobile MOBA (Multiplayer Online Battle Arena) terkenal di Indonesia, Mobile Legends selalu menghadirkan beragam hero dan pertandingan seru setiap harinya. Game ini banyak digandrungi atau disukai oleh anak remaja pada era milenial sekarang ini karna dinilai memiliki keseruan tersendiri dalam bermain game (Putro, 2018).
Multiplayer Online Battle Arena orang sering menyebutnya dengan sebutan MOBA yaitu permaianan game mobile yang setiap pemainnya hanya dapat mengontrol satu karakter di dalam satu tim, dengan gameplay dua tim yang setiap timnya bertujuan untuk menghancurkan base musuh atau turet terakhir yang paling besar dan berada pada base musuh. Game tersebut mempunyai gameplay berisikan 10 pemain yang terbagi menjadi 2 tim yaitu setiap tim memiliki 5 pemain, satu pemain yang hanya dapat mengendalikan satu karakter dalam game yang disebut dengan hero, setiap karakter atau hero 
masing-masing memiliki kemampuan yang berbeda yaitu kemapuan assassin, tank, mage, fighter, support, dan marksman.

Adanya permasalahan yang sering terdapat saat para pemain melakukan permainan game secara sendiri atau solo maupun dalam team. Terdapat beberapa mode permaian dalam game Mobile Legend ini yaitu : Classic, Brawl, VS Ai, Custom, Ranked, dan yang baru adalah Magic Chesee. Pada beberapa kasus dalam permainan Ranked Match sering banyak pemain yang mengeluh di karenakan rank game mereka terus menurun yang diakibatkan oleh kekalahan dalam permaian mode Ranked (Atmaja \& Sandy, 2020). Di lihat dari kasus ada tersebut penulis dapat menyimpulkan sehingga mendapatkan beberapa faktor penyebab yang mengakibatkan kekalahan dari permainan mereka. Contoh factor penyebab permasalahan tersebut antara lain belum mengusai hero dengan matang atau mencoba hero baru pada mode rank yang belum dikuasai, pemilihan item atau equipment yang kurang tepat bahkan tidak cocok pada hero yang digunakan, koneksi jaringan yang kurang stabil namun dipaksa untuk bermain ranked match sehingga dalam permainan mengakibatkan hero bergerah patah-patah bahkan terdian atau sering disebut lag, dan dalam penyusunan tim yang kurang tepat bahkan salah atau kurang optimal (Kurniawan \& Andono, 2017). Dari beberapa faktor permasalahan yang sudah disebutkan sebelumnya, penulis mengambil satu buah masalah yang penting dan sering dihadapi saat bermain dengan team random yaitu susunan tim yang kurang baik atau optimal.

Naïve Bayes adalah metode untuk mengklasifikasi dengan menggunakan metode statistic dan probabilitas yang dikemukakan oleh ilmuwan Inggris yaitu Thomas Bayes (Rifai, Jatnika, \& Valentino, 2019) (Syarli, 2016). Naïve Bayes adalah penghitungan secara statistik untuk memprediksi peluang yang akan datang berdasarkan pengalaman atau permasalahan yang dihadapi sebelumnya sehingga dikenal sebagai Teorema Bayes (Pratiwi \& Nugroho, 2016). Ciri paling yang utama pada metode Naïve Bayes Classifier yaitu asumsi yang kuat dengan independensi dari kejadian atau kondisi, keuntungan pada penggunan metode ini hanya membutuhkan jumlah data pelatihan yaitu training data yang cukup kecil untuk dapat menentukan estimasi dan parameter yang diperlukan pada proses pengklasifikasian (Sabransyah, Nasution, \& Amijaya, 2017). Oleh karena itu yang diasumsikan dijadikan sebagai variable independent, untuk menentukan klasifikasi membutuhkan varian dari suatu variable dalam kelas bukan seluruhnya dari matriks kovarians (Rifqo \& Wijaya, 2017).

Adapun tujuan dari penelitian ini adalah untuk bisa mengetahui tingkat kemenangan dalam permainan mode ranked match. Ranked Match merupakan salah satu pertandingan yang bergengsi di Mobile Legends. Dengan hadirnya Ranked Match ini memungkinkan pemainnya dapat mengukur kemampuan dan rekan timnya dalam bertanding arena Mobile Legends. Apabila pemain Mobile Legends berhasil memenangkan Ranked Match maka akan naik peringkat (Rank).

\section{Metodologi}

\subsection{Klasifikasi demonstrate}

Klasifikasi demonstrate yang menjelaskan dan mengelompokan kelas information agar dapat memprediksi objek yang nama kelasnya tidak diketahui Algoritma Klasifikasi yang sering digunakan secara luas, yaitu Decision (classification trees), Bayesian classifiers (Naïve Bayes classifiers), Neural systems, Analisa Statistik, Algoritma Genetika, Unpleasant sets, knearest neighbor, Metode Run the show Based, Memory based thinking, dan Bolster vector machines (SVM) (As'ad, 2016).

\subsection{Tahap Penelitian}

Beberapa tahapan penelitian yang telah di lalui untuk menyelesaikan penelitian digambarkan pada Gambar 1 di bawah ini.

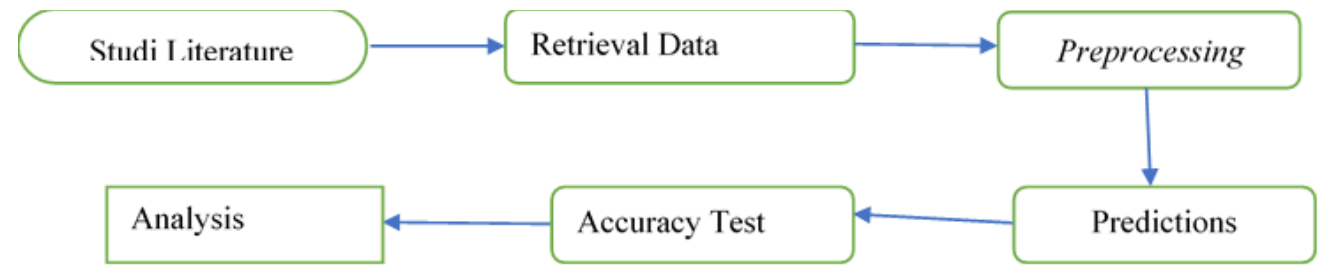

Gambar 1. Tahapan penelitian 
Gambar 1 merupakan gambaran dari rangkaian penelitian yang harus dilakukan pada penelitian ini. Studi literatur adalah tahap awal yang dikerjakan untuk mempelajari teori yang bersangkutan dengan penelitian ini termasuk di dalamnya adalah mempelajari penelitian terdahulu guna untuk mendukung penelitian. Beberapa literatur yang akan digunakan adalah site, prosiding, jurnal, buku dan publikasi ilmiah. Penggunaan informasi dikerjakan setelah teori selesai dipelajari. Informasi diambil dari situs https://gamebrott.com/ merupakan information hero-hero yang sedang meta. Kemudian tahap selanjutnya preproscessing digunakan untuk melakukan seleksi information dan penghapusan information yang tidak sesuai agar siap untuk dikerjakan. Tahapan seterusnya adalah classification Gullible Bayes untuk mendapatkan show classificaton. Setelah demonstrate diperoleh, lalu kita akan mencoba akurasi show yang diperoleh. Dari show yang kita peroleh kemudian dapat dilanjutkan tahap prediksi.

\subsection{Naive Bayes}

Metode naive bayes berperan buat menciptakan model klasifikasi dengan metode menghitung probabilitas anggota suatu kelas. Secara universal rumus metode Naïve Bayes diperlihatkan pada persamaan 1 (Kurniawan \& Andono, 2017). Penjelasan rumus merupakan bagaikan berikut: $\mathrm{x}$ merupakan information yang belum dikenal kelasnya, $\mathrm{c}$ merupakan hipotesis $\mathrm{x}$ yang ialah sesuatu ke alas khusus,

$$
P(c \mid x)=\frac{P(x \mid c) P(c)}{P(x)}
$$

Navie bayes sering dipakai buat informasi dengan tipe kategorikal tetapi bisa juga dipakai oleh informasi kontinu yang dilakukan dengan teknik special, dengan dihitungnya distribusi gaussian. Rumus itu didapat dengan persamaan dua. Penjelasan rumus merupakan bagaikan berikut:

$$
P\left(X_{i}=x_{i} \mid Y=y_{i}\right)=\frac{1}{\sqrt{2 \pi(\sigma)}} e^{\frac{-\left(x_{i}-\mu\right)^{2}}{2(\sigma)^{2}}}
$$

$\mu$ adalah rata-rata data, sedangkan $\sigma$ merupakan standar deviasi

Agar dapat menemukan hasil dari moder diatas yang kita perlukan menguji akurasi. Rumus untuk menguji akurasi adalah

$$
\text { Akurasi }=\frac{\text { Jumlah data yang diprediksi benar }}{\text { Jumlah prediksi yang dilakukan }}
$$

\begin{tabular}{|c|c|c|c|c|c|c|}
\hline War ke - & Nama Hero & $\mathrm{Ae}$ & $\mathrm{Db}$ & Off & Def & Hasil \\
\hline \multirow{11}{*}{1} & Balmand & Tidak Sakit & Sangat Keras & Sakit & Rendah & Menang \\
\hline & Yss & Sakit & Normal & Sakit & Sulit & Menang \\
\hline & Harley & Sakit & Lembek & Normal & Sedang & Menang \\
\hline & Ruby & Normal & Keras & Tidak Sakit & Sangat Sulit & Menang \\
\hline & Akai & Normal & Sangat Keras & Normal & Sedang & Menang \\
\hline & & & & & & \\
\hline & Kagura & Sangat Sakit & Keras & Tidak Sakit & Sangat Sulit & Kalah \\
\hline & Moskov & Tidak Sakit & Lembek & Sangat Sakit & Sangat Sulit & Kalah \\
\hline & Karina & Tidak Sakit & Lembek & Sakit & Sulit & Kalah \\
\hline & Saber & Tidak Sakit & Normal & Sangat Sakit & Sulit & Kalah \\
\hline & Hilda & Normal & Sangat Keras & Normal & Rendah & Kalah \\
\hline \multirow{6}{*}{2} & Lancelot & Tidak Sakit & Normal & Sangat Sakit & Sangat Sulit & Kalah \\
\hline & Irithel & Tidak Sakit & Lembek & Sakit & Sangat Sulit & Kalah \\
\hline & Hylos & Normal & Sangat Keras & Tidak Sakit & Rendah & Kalah \\
\hline & Gord & Sangat Sakit & Lembek & Tidak Sakit & Sulit & Kalah \\
\hline & Akai & Normal & Sangat Keras & Normal & Sedang & Kalah \\
\hline & Bruno & Sakit & Lembek & Sangat Sakit & Sedang & Menang \\
\hline
\end{tabular}

Table 1. Data Traingin Pertandingan 


\begin{tabular}{|l|l|l|l|l|l|}
\hline Cyclops & Sangat Sakit & Lembek & Tidak Sakit & Sulit & Menang \\
\hline Johnson & Normal & Sangat Keras & Tidak Sakit & Sedang & Menang \\
\hline Balmand & Tidak Sakit & Sangat Keras & Sakit & Rendah & Menang \\
\hline Vexana & Sangat Sakit & Lembek & Normal & Sangat Sulit & Menang \\
\hline
\end{tabular}

Pada tabel 1 yang akan dijadikan sampel perhitungan adalah data pertandingan ke -1 untuk dapat menentukan statistic penelitian selanjutnya, pada table diatas telah menentukan hero-hero yang masing-masing memiliki kemampuan yang berbeda.

\section{Hasil dan Pembahasan}

Berikut merupakan langkah yang digunakan untuk menghitung prediksi kemenangan menggunakan Naive Bayes.

1) Menghitung probabilitas hero tiap tim.

Menghitung probabilitas hero pada tim Allies

Balmond

$\mathrm{p}(\mathrm{ae}=($ tidak sakit $\mid \mathrm{y}=$ menang $)=49 / 150=$ 0,3267

$\mathrm{p}(\mathrm{db}=($ keras $\mid \mathrm{y}=$ menang $) \quad=41 / 150=$ 0,2733

$\mathrm{p}(\mathrm{off}=($ sakti $\mid \mathrm{y}=$ menang $) \quad=38 / 150=$ 0,2533

$\mathrm{p}(\operatorname{dif}=($ rendah $\mid \mathrm{y}=$ menang $)=24 / 150=$ 0,16

p(ae tidaksakti $*$ db keras $*$ off sakti $*$ dif rendah|y =menang)

menang $=$

$$
\begin{gathered}
(0,3267 * 0,2733 * 0,2533 * 0.16) *(0,5) \\
=0,001810
\end{gathered}
$$

yss

$\mathrm{p}(\mathrm{ae}=($ sakti $\mid \mathrm{y}=$ menang $)=24 / 150=0,16$

$\mathrm{p}(\mathrm{db}=($ normal $\mid \mathrm{y}=$ menang $)=33 / 150=$

0,22

$\mathrm{p}($ off $=($ sakti $\mid \mathrm{y}=$ menang $)=38 / 150=$ 0,2533

$\mathrm{p}(\operatorname{dif}=($ sulit $\mid \mathrm{y}=$ menang $)=50 / 150=$ 0,3333

$\mathrm{p}($ ae sakti $* \mathrm{db}$ normal $*$ off sakti $*$ dif

sulit|y =menang)

menang $=$

$$
\begin{gathered}
(0,16 * 0,22 * 0,2533 * 0,3333) *(0,5) \\
=0,001486
\end{gathered}
$$

harley

$$
\begin{array}{ll}
\mathrm{p}(\mathrm{ae}=(\text { sakti } \mid \mathrm{y}=\text { menang }) & =24 / 150 \\
=0,16 & \\
\mathrm{p}(\mathrm{db}=(\text { lembek } \mid \mathrm{y}=\text { menang }) & =44 / 150
\end{array}
$$

$\mathrm{p}(\mathrm{off}=($ normal $\mid \mathrm{y}=$ menang $) \quad=38 / 150=$

$$
0,2533
$$

$\mathrm{p}($ dif $=($ sedang $\mid \mathrm{y}=$ menang $) \quad=24 / 150=$ 0,28

$\mathrm{p}($ ae sakti $*$ db lembek $*$ off normal $*$ dif sedang $\mid \mathrm{y}=$ menang)

menang

$$
(0,16 * 0,2933 * 0,2533 * 0,28) *(0,5)
$$$$
=0,001665
$$

ruby

$$
\begin{aligned}
& \mathrm{p}(\text { ae }=(\text { normal } \mid \mathrm{y}=\text { menang }) \quad=47 / 150 \\
& =0,3133 \\
& \mathrm{p}(\mathrm{db}=(\text { keras } \mid \mathrm{y}=\text { menang }) \\
& \quad=0,2133 \\
& \mathrm{p}(\text { off }=(\text { tidak sakit } \mid \mathrm{y}=\text { menang }) \quad=41 / 150 \\
& \quad=0,2733 \\
& \mathrm{p}(\text { dif }=(\text { sangat sulit } \mid \mathrm{y}=\text { menang }) \\
& \quad 34 / 150=0,2367 \\
& \mathrm{p}(\text { ae normal } * \text { db keras } * \text { off tidak sakit } * \\
& \text { dif sangat sulit } \mid \mathrm{y}=\text { menang }) \\
& \text { menang }= \\
& (0,3133 * 0,2133 * 0,2733 * 0,2267) *(0,5) \\
& \quad=0,002071
\end{aligned}
$$

akai

$\mathrm{p}(\mathrm{ae}=($ normal $\mid \mathrm{y}=$ menang $) \quad=47 / 150$

$$
=0,3133
$$

$\mathrm{p}(\mathrm{db}=($ sangat keras $\mid \mathrm{y}=$ menang $)=41 / 150$ $=0,2733$

$\mathrm{p}(\mathrm{off}=($ normal $\mid \mathrm{y}=$ menang $) \quad=38 / 150$ $=0,2533$

$\mathrm{p}($ dif $=($ sedang $\mid \mathrm{y}=$ menang $) \quad=$ $24 / 150=0,28$

$\mathrm{p}($ ae normal $* \mathrm{db}$ sangat keras $*$ off normal $*$ dif sedang $\mid \mathrm{y}=$ menang)

menang

$$
\begin{gathered}
(0,3133 * 0,2733 * 0,2533 * 0,28) *(0,5) \\
=0,003038
\end{gathered}
$$

2) Bandingankan hasil probabilitas menang pada kedua tim

3) Mendapatkan nilai persentase dari hasil probabilitas MENANG pada kedua tim 


$$
\begin{aligned}
& \text { Allies }=\frac{1,4079 e-14}{(1,4079 e-14+2,92175 e-14)} * 100 \%=33 \% \\
& \text { Enemy }=\frac{2,92175 e-14}{(1,4079 e-14+2,92175 e-14)} * 100 \%=67 \%
\end{aligned}
$$

Di mana Criteria_range1 merupakan array untuk kriteria pertama.

Criteria1 merupakan kriteria pertama yang akan dicocokkan.

Contoh Implementasi:

COUNTIF (I2:I360;Tidak

Sakit;M2:M360;Menang)*150

Penjelasan rumus:

1. I2:I360 adalah range yang digunakan untuk memanggil attribut
2. Attribut 1 adalah ABILITY EFFECT pada hero.

3. M2:M360 adalah range yang digunakan untuk memanggil label MENANG.

4. 150 adalah total nilai data training dengan kondisi MENANG.

Tanda $*$ adalah sebagai perkalian untuk mengkalikan dengan proses selanjutnya yang sesuai dengan tahapan metode Naive Bayes. Pengujian akan dilakukan dengan percobaan sebanyak 20 pertandingan dengan jenis pertandingan ranked match.

Tabel 2 . Pengujian Sistem

\begin{tabular}{|c|c|c|c|c|c|}
\hline \multirow{2}{*}{ PERTANDINGAN } & \multicolumn{2}{|c|}{ PREDIKS } & \multicolumn{2}{c|}{ REAL } & \multirow{2}{*}{ HASIL } \\
\cline { 2 - 5 } & $\begin{array}{l}\text { TIM } \\
\text { ALLIES }\end{array}$ & $\begin{array}{l}\text { TIM } \\
\text { ENEMY }\end{array}$ & $\begin{array}{l}\text { TIM } \\
\text { ALLIES }\end{array}$ & $\begin{array}{l}\text { TIM } \\
\text { ENEMY }\end{array}$ & \\
\hline 1 & Menang & Kalah & Menang & Kalah & Benar \\
\hline 2 & Kalah & Menang & Menang & Kalah & Salah \\
\hline 3 & Menang & Kalah & Menang & Kalah & Benar \\
\hline 4 & Kalah & Menang & Menang & Kalah & Salah \\
\hline 5 & Kalah & Menang & Kalah & Menang & Benar \\
\hline 6 & Kalah & Menang & Kalah & Menang & Benar \\
\hline 7 & Menang & Kalah & Menang & Kalah & Benar \\
\hline 8 & Menang & Kalah & Kalah & Menang & Salah \\
\hline 9 & Menang & Kalah & Kalah & Kalah & Salah \\
\hline 10 & Kalah & Menang & Menang & Kalah & Salah \\
\hline 11 & Kalah & Menang & Kalah & Menang & Benar \\
\hline 12 & Menang & Kalah & Menang & Kalah & Benar \\
\hline 13 & Kalah & Menang & Kalah & Menang & Benar \\
\hline 14 & Menang & Kalah & Menang & Kalah & Benar \\
\hline 15 & Menang & Kalah & Menang & Kalah & Benar \\
\hline 16 & Menang & Kalah & Menang & Kalah & Benar \\
\hline 17 & Menang & Kalah & Menang & Kalah & Benar \\
\hline 18 & Kalah & Menang & Kalah & Menang & Benar \\
\hline 19 & Menang & Kalah & Menang & Kalah & Benar \\
\hline 20 & Kalah & Menang & Kalah & Menang & Benar \\
\hline
\end{tabular}

Hasil dari Analisa Pengujian Program sehabis dicoba pengujian dengan 20 pertandingan ranked macth di miliki 15 pertandingan dengan prediksi benar serta 5 pertandingan yang salah dengan prediksi. Berikut merupakan perhitungan tingkatan akurasi dari uji coba program: 


\section{Tingkat Akurasi Benar}

$\frac{\sum B}{\sum T} * 100 \%=\frac{16}{20}=75 \%$

Tingkat Error

$\frac{\Sigma S}{\Sigma T} * 100 \%=\frac{4}{20}=25 \%$

Penjelasan:

$\sum B=$ jumlah percobaan dengan nilai benar $\sum S=$ jumlah percobaan dengan nilai salah $\sum \mathrm{T}=$ jumlah seluruh percobaan

Hasil dari pengujian program tersebut didapatkan tingkatan akurasinya merupakan $75 \%$ sebaliknya tingkatan erorrnya sebesar $25 \%$.

\section{Kesimpulan}

setelah melakukan penelitian tentang game berbasis online yaitu Mobile Legend. Dengan menerapkan Metode algoritma naive bayes dan melakukan pengujian algoritma naïve bayes kepada game mobile legend hasil yang didapatkan pada tabel system dengan mengunakan pengujian ini yaitu naïve bayes adalah sebanyak 20 pertandingan dengan prediksi benar sebanyak 11 di tim allies dan sebanyak 9 di tim enemy lalu pada tabel real dalam 20 pertandingan kemenangan tim allies yaitu sebanyak 12 kali kemenangan dari tim enemy sedangkan pada tim enemy hanya memiliki 8 kali kemenangan dari tim allies, lalu jumlah hasil BENAR sebanyak 15 dan hasil salah hanya sebanyak 5 dan dapat dipresentasekan dengan menggunakan metode naïve bayes ini menghasilkan $75 \%$ tingkat akurasi benar dan hanya $25 \%$ saja tingkat akurasi salah.

\section{Referensi}

As'ad, B. (2016). Prediksi Keputusan Menggunakan Metode Klasifikasi Naïve Bayes, One-R, dan Decision Tree. Jurnal Penelitian Komunikasi dan Opini Publik, 1-10.

Atmaja, \& Sandy, E. H. (2020). Prediksi Kemenangan eSport DOTA 2 Berdasarkan Data Pertandingan. Aviation Electronics, Information Technology,

Telecommunications, Electricals, and Controls (AVITEC), 1-8.

Kurniawan, N. B., \& Andono, P. N. (2017). Prediksi Kemenangan Bot Dota 2 Menggunakan Metode Naive Bayes. 1-10.

Pratiwi, R. W., \& Nugroho, Y. S. (2016). Prediksi Rating Film Menggunakan Metode Naïve Bayes. Jurnal Teknik Elektro, 1- 4.
Putro, A. C. (2018). Sistem Prediksi Kemenangan Tim pada Game Mobile Legends dengan Metode Naive Bayes. 1-11.

Rifai, M. F., Jatnika, H., \& Valentino, B. (2019). Penerapan Algoritma Naïve Bayes Pada Sistem Prediksi Tingkat Kelulusan Peserta Sertifikasi Microsoft Office Specialist (MOS). PETIR (Jurnal Pengkajian Dan Penerapan Teknik Informatika), 12(2), 131144. doi:10.33322/petir.v12i2.471

Rifqo, M. H., \& Wijaya, A. (2017). Implementasi Algoritma Naive Bayes dalam Penentuan Pemberian Kredit. Jurnal Pseudocode, 1-9.

Sabransyah, M., Nasution, Y. N., \& Amijaya, F. D. (2017). Aplikasi Metode Naive Bayes dalam Prediksi Risiko Penyakit Jantung. Jurnal EKSPONENSIAL, 8(2), 111-117.

Syarli, S. (2016). Metode Naive Bayes Untuk Prediksi Kelulusan (Studi Kasus: Data Mahasiswa Baru Perguruan Tinggi). Jurnal Ilmiah Ilmu Komputer, 2(1), 22-26. 